\title{
Insecticide resistance and target site mutations (G119S ace-1 and L1014F kdr) of Culex pipiens in Morocco
}

\author{
Fatim-Zohra Tmimi ${ }^{1,2}$, Chafika Faraj ${ }^{3}$, Meriem Bkhache ${ }^{1}$, Khadija Mounaji ${ }^{2}$, Anna-Bella Failloux ${ }^{4}$ \\ and M'hammed Sarih ${ }^{1 *}$
}

\begin{abstract}
Background: Control of the mosquito vector Culex pipiens with insecticides is the main way to control arboviruses that the species can transmit such as West Nile virus (WNV) and Rift Valley fever virus (RVFV). However, its efficiency has been hampered by the emergence of insecticide resistance. Little is known about the insecticide-resistance status and underlying resistance mechanisms of field-collected populations of Cx. pipiens in Morocco.

Methods: Mosquito adults from Mohammadia city in Morocco were reared from immature stages. The level of their susceptibility to insecticides was assessed using standard WHO bioassay. The two forms of the CX. pipiens complex and their hybrids were identified by a multiplex PCR. Identified mosquitoes were then tested for the presence of the G119S ace-1 and L1014F kdr mutations using PCR-RFLP and PCR assays, respectively.

Results: WHO bioassays indicated that $C x$. pipiens was resistant to all tested insecticides: lambda-cyhalothrin (49\% mortality), permethrin (63\% mortality), DDT (16\% mortality), malation (52\% mortality) and bendiocarb (39\% mortality). The frequency of the $119 \mathrm{~S}$ allele was almost identical in the pipiens form and hybrids ( 0.11 and 0.15 , respectively) whereas it remained low in the molestus form (0.03). No significant correlation was observed between the G119S allele and the resistance phenotype to two tested insecticides (malathion and bendiocarb). The frequency of the L1014F allele was identical in the pipiens form and hybrids (0.44) whereas it was low in the molestus form (0.36) but no significant difference was detected $\left(X^{2}=1.46, d f=1, P=0.225\right)$. The presence of the L1014F $k d r$ mutation was significantly associated with resistance to three tested insecticides in pipiens form ( $P=0.0019, P=0.0023$ and $P=0.023$, respectively, to lambda-cyhalothrin, permethrin and DDT) whereas no significant correlation was observed between the L1014F kdr mutation and resistance phenotype in molestus form and hybrids to the three tested insecticides.

Conclusion: These findings showed that wild populations of $C x$. pipiens have developed resistance against the main insecticide families with different modes of action: organochlorines (DDT), organophosphates (malathion), carbamates (bendiocarb), pyrethroids (lambda-cyhalothrin, permethrin). Therefore, urgent action should be taken to manage the resistance in this species to maintain the effectiveness of arbovirus control.
\end{abstract}

Keywords: Culex pipiens, L1014F kdr, G119S ace-1, Insecticides, Resistance, Morocco

\footnotetext{
* Correspondence: mhammed.sarih@pasteur.ma

${ }^{1}$ Institut Pasteur du Maroc, Service de Parasitologie et des Maladies

Vectorielles, Place Louis Pasteur, 20360 Casablanca, Morocco

Full list of author information is available at the end of the article
} 


\section{Background}

The Culex pipiens complex mosquitoes are known to be competent vectors of West Nile virus (WNV) and Rift Valley fever virus (RVFV). WNV has been circulating for a very long time in the Mediterranean region [1-4]. In Morocco, several outbreaks of WNV have been reported. The first was in 1996; 94 equine cases including 42 deaths and only one human case was infected [5]. The second was in September and October of 2003 when WNV occurred among horses in Kenitra [6], and the last outbreak was in 2010 in Mohammadia region [7]. Unfortunately, there are no effective vaccines; the only way to limit the infection is the control of mosquitoes, by the most commonly used insecticides, namely organophosphates (temephos) for larvae and pyrethroids for adults. However, the overuse of these products causes the selection of resistance rendering the molecules ineffective for vector control [8].

There are different types of insecticide resistance mechanisms in mosquitoes, but the two main ones are (i) the metabolic resistance, grouping three major families of enzymes involved, glutathione S-transferase (GST), multifunctional monooxygenases (MFOs) and carboxyl-esterase (COE), and (ii) the target site modification, which is due to point mutations in the target of insecticides, thus limiting the binding of the neurotoxin products. Several insecticide target modifications have been described: the $\gamma$-amino butyric acid (GABA Receptors) encoded by $R d l$ gene, the synaptic acethylcholinesterase (AChE1) encoded by the ace-1 gene and the voltage-dependent sodium channel encoded by the $k d r$ gene $[9,10]$. The knockdown resistance $k d r$ gene is the major mechanism responsible for resistance to DDT and PYR, reducing the sensitivity of the receptors to these products in the voltage-gated sodium channel (VGSC) across the neural axon $[8,11]$. This resistance is due to the mutations of $k d r$ gene. Many mutations have been reported, but the most common known to be associated with knockdown resistance in mosquitoes, including $C x$. pipiens, are L1014F by the substitution of a leucine (TTA) by phenylalanine (TTT) and L1014S by the leucine (TTA) to serine (TCA) substitution at codon 1014 [12-14], while the L1014C mutation by the substitution of a leucine (TTA) by cysteine (TGT) has only been reported for $C x$. pipiens molestus from China [15].

The enzyme AChE is the target of OP and CX, which are competitive inhibitors of acethylcholine (Ach). After binding to $\mathrm{AChE}$, the insecticides prevent the hydrolysis of the neurotransmitter Ach in the cholinergic synapses of the central nervous system. As a result, the Ach remains active, and the nervous influx is continued, causing the death of the insect by tetany [16]. In several insects, two genes are described, ace-1 and ace-2, coding for the two synaptic enzymes, AChE1 and AChE2, respectively. Five mutations were described in OPresistant insects [17]. In mosquitoes, including $C x$. pipiens, the most common resistance mutation is G119S in the ace-1 gene [18], located near the catalytic site. The high insensitivity displayed by $C x$. pipiens is due to the substitution of glycine by serine, resulting from a single point mutation GGC to AGC in ace-1 gene [18], allowing a decreased inhibition of the main synaptic enzyme AChE1 by the insecticide [19].

In Morocco, research on insecticide resistance and the mechanisms responsible for insecticide resistance in $C x$. pipiens remain incomplete. The only published studies are those on the resistance level of $C x$. pipiens larvae to temephos $[20,21]$ and recently, our team described the presence of $k d r$ mutation in different forms of $C x$. pipiens [22]. This study aimed to evaluate the insecticide susceptibility status and investigate the target site mutation frequencies (G119S and L1014F) in Cx. pipiens (forms pipiens and molestus, and hybrids) from Mohammadia area that was affected by the last outbreaks of WNV.

\section{Methods \\ Mosquito collection}

Mosquitoes were collected as larvae using the dipping sampling method during summer 2016, from a shanty-

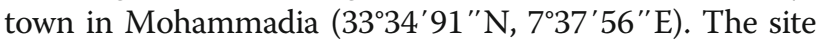
is a suburban habitat with aboveground breeding sites treated with insecticides. The larvae were reared to adults in the laboratory at $28 \pm 1{ }^{\circ} \mathrm{C}$ with a relative humidity of $80 \%$ and a $16: 8 \mathrm{~h}$ photoperiod. Mosquitoes were identified as $C x$. pipiens using the dichotomous software for the identification of mosquitoes in Mediterranean Africa [23].

\section{Bioassays}

Adult bioassays were carried out using WHO protocols, using four sets of 20-25 unfed and 2-5-day-old females. They were exposed to a filter paper impregnated with malathion (OP) at a dose of $5 \%$, bendiocarb $0.1 \%(\mathrm{CX})$, DDT $4 \%$ (OC), lambda-cyalothrin $0.05 \%$ and permethrin $0.75 \%$ (PYR), corresponding to recommended concentrations to kill $100 \%$ of the susceptible individuals [24]. As a control, two sets of 20 unfed 2-5-day-old females were exposed to insecticide-free papers in test tubes. After exposure, mosquitoes were maintained at $28 \pm 1{ }^{\circ} \mathrm{C}$ and $80 \pm 10 \%$ relative humidity, with sugar solution provided. The knockdown effect (KD) was evaluated, at intervals of $10 \mathrm{~min}$, for each test tube impregnated with PYR and DDT. The mortality was recorded $24 \mathrm{~h}$ after exposure. Dead and surviving individuals were frozen at $-20{ }^{\circ} \mathrm{C}$ for molecular analysis.

\section{Molecular identification of $C x$. pipiens forms}

Mosquito DNA was extracted individually using the method of DNAzol according to the manufacturer's 
protocol. Multiplex PCR assays were used to identify $C x$. pipiens complex, described by Banck \&Fonseca [25]. The CQ11 locus was used to distinguish between the two forms of Cx. pipiens (pipiens and molestus) and their hybrids. The DNA fragment size amplified varied between pipiens form (200 bp) and molestus form (250 bp), allowing us to distinguish the two forms in a single PCR reaction.

\section{Detection of G119S mutation}

The presence of G119S was confirmed using diagnostic PCR-RFLP tests described by Weill et al. [26] (30 cycles of $94{ }^{\circ} \mathrm{C}$ for $30 \mathrm{~s}, 52{ }^{\circ} \mathrm{C}$ for $30 \mathrm{~s}$ and $72{ }^{\circ} \mathrm{C}$ for $1 \mathrm{~min}$ ). PCR products were digested by $A l u \mathrm{I}$, restriction enzyme, according to the manufacturer's instructions (Jena Bioscience, Jena, Germany). After digestion, DNA fragments were separated by electrophoresis on $2 \%$ agarose gel and were visualized by ethidium bromide staining under ultraviolet light. Two fragments (74 bp and $120 \mathrm{bp)}$ were obtained for homozygous resistant (RR) mosquitoes. The homozygous susceptible (SS) mosquitoes presented one undigested fragment of $194 \mathrm{bp}$ while the heterozygous resistant (RS) individuals displayed a combined pattern (three fragments: 194, 120 and $74 \mathrm{bp}$ ).

\section{Detection of L1014F mutation}

The presence of L1014F was investigated using two separate PCRs in parallel, one for wild-type susceptible allele detection, using the primers Cgd1, Cgd2 and Cgd3 and the other for leucine-phenylalanine substitution, by replacing Cgd3 by Cgd4. The PCR conditions were $1 \mathrm{~min}$ at $94{ }^{\circ} \mathrm{C}, 2 \mathrm{~min}$ at $48{ }^{\circ} \mathrm{C}$ and $2 \mathrm{~min}$ at $72{ }^{\circ} \mathrm{C}$ for 40 cycles, as described by Martinez Torrez et al. [12], which allow detecting only one form of resistance allele (1014F). Then the DNA fragments were separated by electrophoresis on $1.5 \%$ agarose gel and were visualized by ethidium bromide staining under ultraviolet light.

\section{Data analysis}

The knockdown time for 50\% (the median knockdown time 'kdT50') and $90 \%$ of exposed mosquitoes to PYR and DDT were estimated using a log time probit model (WINDL software). OP and CX do not induce any knockdown effect. The odds ratio (OR) test was applied to estimate the association between ace-1-resistant allele $119 \mathrm{~S}$ and the resistant phenotype and the association between $k d r$-resistant allele $1014 \mathrm{~F}$ and resistant phenotype to different insecticides.

\section{Results}

\section{Insecticide susceptibility bioassays}

Culex pipiens mosquitoes from the study area showed resistance to all tested insecticides (Table 1). For organophosphates (malathion) and carbamates (bendiocarb), resistance was observed in mosquitoes with mortality rates of $52 \%$ and $39 \%$, respectively. While for pyrethroids, resistance was observed in mosquitoes with mortality rates of $49 \%$ and $63 \%$, respectively, for lambdacyalothrin and permethrin. In contrast, DDT caused only $16 \%$ of mortality, which revealed a low susceptibility. $\mathrm{KDT}_{50}$ and $\mathrm{KDT}_{90}$ were $33 \mathrm{~min}$ and $61 \mathrm{~min}$, respectively, for lambda-cyalothrin, and $33 \mathrm{~min}$ and $65 \mathrm{~min}$, respectively, for permethrin (Table 1).

\section{Frequencies of Culex pipiens forms}

After insecticide bioassays, 531 insecticide-resistant and insecticide-susceptible mosquitoes were tested by PCR to identify the $C x$. pipiens forms and hybrids. The highest frequency of insecticide-resistant $C x$. pipiens was observed for the pipiens form with $67 \%, 63 \%, 49 \%, 48 \%$ and $67 \%$, respectively, for malathion, bendiocarb, lambda-cyhalothtrin, permethrin and DDT. Hybrids represented $23 \%, 24 \%, 35 \%, 48 \%$ and $30 \%$, respectively, while the molestus form represented only 10\%, 13\%, $16 \%, 5 \%$ and $2 \%$, respectively (Tables 2 and 3 ).

\section{Genotyping of target-site mutations: ace-1 and kdr}

A total of 531 female mosquitoes, exposed to the five neurotoxin products, were analyzed for the G119S ace-1 and L1014F $k d r$ mutations.

The mosquitoes used for the bioassays with malathion (92 specimens) and bendiocarb (102 specimens) were genotyped for the G119S mutation. The frequency of genotypes is presented in Table 2. When treated with malathion and bendiocard, no homozygote resistant genotypes were detected. Most mosquitoes presented a SS or RS genotype. In addition, 339 mosquitoes were analyzed for the L1014F $k d r$ mutation (Table 3). After exposure to lambda-cyalothrin, most resistant mosquitoes had a RS genotype $(68 \%, 80 \%$ and $78 \%$ for the pipiens, hybrid and molestus forms, respectively) and susceptible mosquitoes presented a SS genotype (61\%, $68 \%$ and $50 \%$ for the pipiens, hybrid and molestus forms, respectively). Only few individuals had RR genotypes.

With permethrin, most resistant mosquitoes were scored as a RS genotype: $67 \%$ for the pipiens form, $72 \%$ for the hybrid form and $50 \%$ for the molestus form. Surprisingly, a high proportion of individuals with susceptible phenotype were scored as a RS genotype: $68 \%$ for the pipiens form, $76 \%$ for the hybrid form and $67 \%$ for the molestus form. Only few individuals presented a RR genotype.

After exposure to DDT, only a low proportion of mosquitoes had a RR genotype: $13 \%$ for the pipiens form and $21.5 \%$ for the hybrid form. Most DDT-resistant mosquitoes had a RS genotype: $71 \%$ for the pipiens from, $71.5 \%$ for the hybrid form and $100 \%$ for the molestus form. Susceptible mosquitoes presented mostly a SS 
Table 1 Mortality and knockdown effect of insecticides on Cx. pipiens in Mohammadia, Morocco

\begin{tabular}{|c|c|c|c|c|c|c|}
\hline \multirow[t]{2}{*}{ Insecticide } & \multicolumn{2}{|c|}{ Exposed mosquitoes } & \multicolumn{2}{|c|}{ Control mosquitoes } & \multirow[t]{2}{*}{$\mathrm{kdT}_{50}(\min )(95 \% \mathrm{Cl})$} & \multirow[t]{2}{*}{$\mathrm{kdT}_{90}(\min )(95 \% \mathrm{Cl}$} \\
\hline & $n$ & Mortality (\%) & $n$ & Mortality (\%) & & \\
\hline Lymbda-cyhalothrin (0.05\%) & 111 & 49 & 40 & 0 & $33(30.52-34.95)$ & $61(56.23-69.20)$ \\
\hline Permethrin (0.75\%) & 118 & 63 & 40 & 0 & $33(30.07-35.07)$ & 65 (59.09-74.43) \\
\hline DDT (4\%) & 110 & 16 & 40 & 0 & no kd & no kd \\
\hline Malathion (5\%) & 90 & 52 & 40 & 0 & - & - \\
\hline Bendiocarb (0.1\%) & 102 & 39 & 40 & 0 & - & - \\
\hline
\end{tabular}

Abbreviations: $k d T_{50}$ and $k d T_{90}$ knock down time for $50 \%$ and $90 \%$, respectively, of exposed mosquitoes with confidence intervals (Cl) at $5 \%$ level provided by WINDL software, $n$ number of mosquitoes

genotype: $80 \%$ for the pipiens form and $50 \%$ for the hybrid form.

The frequencies of the $119 \mathrm{~S}$ allele and the $1014 \mathrm{~F}$ allele are shown in Tables 2 and 3. The frequency of the 119S allele was almost identical in the pipiens form and hybrids, 0.11 and 0.15 , respectively, whereas it was low in the molestus form (0.03). The frequency of the 1014F allele was identical in the pipiens and hybrid forms (0.44) whereas it was low in the molestus form (0.36) but no significant difference was detected $\left(\chi^{2}=1.46, d f=1, P=0.225\right)$.

The diagnostic test using ace-1 as a resistance marker in $C x$. pipiens differed between malathion and bendiocarb, with a high specificity for both ( $72 \%$ and $95 \%$, respectively) but markedly lower sensitivity (33\% and $21 \%$, respectively) (Table 4). The $k d r$ as a resistance marker in $C x$. pipiens differed between the three insecticides, with a high sensitivity ( 86 for lambda-cyhalothrin, 84 for permethrin and 87 for DDT) but markedly a lower specificity $(63,26$, and 56 , respectively) (Table 4).

No significant association was shown between the G119S allele and the resistance phenotype to two tested insecticides (malathion and bendiocarb) (Table 5). The presence of the L1014F $k d r$ mutation was significantly associated with resistance to three tested insecticides in

Table 2 Frequencies of ace-1 mutation according to the phenotype (resistant/susceptible) of different forms of $C x$. pipiens in Mohammadia, Morocco

\begin{tabular}{|c|c|c|c|c|c|c|c|c|}
\hline \multirow[t]{3}{*}{ Insecticide } & \multirow[t]{3}{*}{ Cx. pipiens form } & \multirow[t]{3}{*}{ Phenotype } & \multirow[t]{3}{*}{$n(\%)$} & \multirow{3}{*}{$\begin{array}{l}\text { Insecticide } \\
\text { resistance (\%) }\end{array}$} & \multicolumn{3}{|c|}{ Genotype (\%) } & \multirow{3}{*}{$\begin{array}{l}\text { Frequency } \\
\text { of allele }\end{array}$} \\
\hline & & & & & SS & RS & $\mathrm{RR}$ & \\
\hline & & & & & $n(\%)$ & $n(\%)$ & $n(\%)$ & \\
\hline \multirow[t]{9}{*}{ Malathion } & \multirow[t]{3}{*}{ Cx.p.pipiens } & Susceptible & $30(46.0)$ & & $22(73.0)$ & $8(27.0)$ & 0 & 0.13 \\
\hline & & Resistant & $35(54.0)$ & 67 & $25(71.5)$ & $10(28.5)$ & 0 & 0.14 \\
\hline & & Total & 65 & & $47(72.0)$ & $18(28.0)$ & 0 & 0.14 \\
\hline & \multirow[t]{3}{*}{ Hybrid } & Susceptible & $8(40.0)$ & & $5(62.5)$ & $3(37.5)$ & 0 & 0.19 \\
\hline & & Resistant & $12(60.0)$ & 23 & $6(50.0)$ & $6(50.0)$ & 0 & 0.25 \\
\hline & & Total & 20 & & $11(55.0)$ & $9(45.0)$ & 0 & 0.22 \\
\hline & \multirow[t]{3}{*}{ Cx.p. molestus } & Susceptible & $2(28.5)$ & & $2(100)$ & 0 & 0 & 0 \\
\hline & & Resistant & $5(71.5)$ & 10 & $4(80.0)$ & $1(20.0)$ & 0 & 0.10 \\
\hline & & Total & 7 & & $6(86.0)$ & $1(14.0)$ & 0 & 0.07 \\
\hline \multirow[t]{9}{*}{ Bendiocarb } & \multirow[t]{3}{*}{ Cx.p.pipiens } & Susceptible & $23(37.0)$ & & $22(96.0)$ & $1(4.0)$ & 0 & 0.02 \\
\hline & & Resistant & $39(63.0)$ & 63 & $31(79.5)$ & $8(20.5)$ & 0 & 0.10 \\
\hline & & Total & 62 & & $53(85.0)$ & $9(15.0)$ & 0 & 0.07 \\
\hline & \multirow[t]{3}{*}{ Hybrid } & Susceptible & $16(52.0)$ & & $15(94.0)$ & $1(6.0)$ & 0 & 0.03 \\
\hline & & Resistant & $15(48.0)$ & 24 & $10(67.0)$ & $5(33.0)$ & 0 & 0.17 \\
\hline & & Total & 31 & & $25(81.0)$ & $6(19.0)$ & 0 & 0.09 \\
\hline & \multirow[t]{3}{*}{ Cx.p. molestus } & Susceptible & $1(11.0)$ & & $1(100)$ & 0 & 0 & 0 \\
\hline & & Resistant & $8(89.0)$ & 13 & $8(100)$ & 0 & 0 & 0 \\
\hline & & Total & 9 & & $9(100)$ & 0 & 0 & 0 \\
\hline
\end{tabular}


Table 3 Frequencies of $k d r$ mutation according to the phenotype (resistant/susceptible) of different forms of Cx. pipiens in Mohammadia, Morocco

\begin{tabular}{|c|c|c|c|c|c|c|c|c|}
\hline \multirow[t]{2}{*}{ Insecticide } & \multirow{2}{*}{$\begin{array}{l}\text { Cx. pipiens } \\
\text { form }\end{array}$} & \multirow[t]{2}{*}{ Phenotype } & \multirow[t]{2}{*}{$n(\%)$} & \multirow{2}{*}{$\begin{array}{l}\text { Insecticide } \\
\text { resistance (\%) }\end{array}$} & \multicolumn{3}{|l|}{ Genotype } & \multirow{2}{*}{$\begin{array}{l}\text { Frequency } \\
\text { of allele }\end{array}$} \\
\hline & & & & & $\begin{array}{l}\text { SS } \\
n(\%)\end{array}$ & $\begin{array}{l}\text { RS } \\
n(\%)\end{array}$ & $\begin{array}{l}\text { RR } \\
n(\%)\end{array}$ & \\
\hline \multirow[t]{9}{*}{ Lambda-cyhalothrin } & \multirow[t]{3}{*}{ Cx.p.pipiens } & Susceptible & $23(45.0)$ & & $14(61.0)$ & $8(35.0)$ & $1(4.0)$ & 0.39 \\
\hline & & Resistant & $28(55.0)$ & 49 & $4(14.0)$ & $19(68.0)$ & $5(18.0)$ & 0.52 \\
\hline & & Total & 51 & & $18(35.0)$ & $27(53.0)$ & $6(12.0)$ & 0.38 \\
\hline & \multirow[t]{3}{*}{ Hybrid } & Susceptible & $25(56.0)$ & & $17(68.0)$ & $6(24.0)$ & $2(8.0)$ & 0.20 \\
\hline & & Resistant & $20(44.0)$ & 35 & $2(10.0)$ & $16(80.0)$ & $2(10.0)$ & 0.50 \\
\hline & & Total & 45 & & $19(42.0)$ & $22(49.0)$ & $5(11.0)$ & 0.35 \\
\hline & \multirow[t]{3}{*}{ CX.p. molestus } & Susceptible & $6(40.0)$ & & $3(50.0)$ & $3(50.0)$ & 0 & 0.25 \\
\hline & & Resistant & $9(60.0)$ & 16 & $2(22.0)$ & $7(78.0)$ & 0 & 0.39 \\
\hline & & Total & 15 & & $5(33.0)$ & $10(67.0)$ & 0 & 0.33 \\
\hline \multirow[t]{9}{*}{ Permethrin } & \multirow[t]{3}{*}{ Cx.p.pipiens } & Susceptible & $28(57.0)$ & & $9(32.0)$ & $19(68.0)$ & 0 & 0.34 \\
\hline & & Resistant & $21(43.0)$ & 48 & $3(14.0)$ & $14(67.0)$ & $4(19.0)$ & 0.52 \\
\hline & & Total & 49 & & $12(24.5)$ & $33(67.0)$ & $4(8.0)$ & 0.42 \\
\hline & \multirow[t]{3}{*}{ Hybrid } & Susceptible & $37(64.0)$ & & $7(19.0)$ & $28(76.0)$ & $2(5.0)$ & 0.43 \\
\hline & & Resistant & $21(36.0)$ & 48 & $3(14.0)$ & $15(72.0)$ & $3(14.0)$ & 0.50 \\
\hline & & Total & 58 & & $10(17.0)$ & $43(74.0)$ & $5(9.0)$ & 0.45 \\
\hline & \multirow[t]{3}{*}{ Cx.p. molestus } & Susceptible & $9(82.0)$ & & $3(33.0)$ & $6(67.0)$ & 0 & 0.33 \\
\hline & & Resistant & $2(18.0)$ & 5 & $1(50.0)$ & $1(50.0)$ & 0 & 0.25 \\
\hline & & Total & 11 & & $4(36.0)$ & $7(64.0)$ & 0 & 0.32 \\
\hline \multirow[t]{9}{*}{ DDT } & \multirow[t]{3}{*}{ Cx.p.pipiens } & Susceptible & $10(14.0)$ & & $8(80.0)$ & $2(20.0)$ & 0 & 0.10 \\
\hline & & Resistant & $62(86.0)$ & 67 & $10(16.0)$ & $44(71.0)$ & $8(13.0)$ & 0.48 \\
\hline & & Total & 72 & & $18(25.0)$ & $46(64.0)$ & $8(11.0)$ & 0.43 \\
\hline & \multirow[t]{3}{*}{ Hybrid } & Susceptible & $4(12.5)$ & & $2(50.0)$ & $2(50.0)$ & 0 & 0.25 \\
\hline & & Resistant & $28(87.5)$ & 30 & $2(7.0)$ & $20(71.5)$ & $6(21.5)$ & 0.57 \\
\hline & & Total & 32 & & $4(12.0)$ & $22(69.0)$ & $6(19.0)$ & 0.53 \\
\hline & \multirow[t]{3}{*}{ CX.p. molestus } & Susceptible & $4(67.0)$ & & 0 & $4(100)$ & 0 & 0.50 \\
\hline & & Resistant & $2(33.0)$ & 2 & 0 & $2(100)$ & 0 & 0.50 \\
\hline & & Total & 6 & & 0 & $6(100)$ & 0 & 0.50 \\
\hline
\end{tabular}

Abbreviations: $R R$ homozygote resistant, $R S$ heterozygote resistant,SS homozygote susceptible

the pipiens form $(P=0.0019, P=0.0023$ and $P=0.023$, respectively, to lambda-cyhalothrin, permethrin and DDT). There was no significant correlation between the L1014F $k d r$ mutation and resistance phenotype in the molestus and hybrid forms to three tested insecticides (Table 6).
Discussion

Culex pipiens is an important vector of several diseases including West Nile fever. The lack of an effective vaccine drives the use of insecticides as the main way to control vector populations $[27,28]$. In this study, we investigated the status of resistance of the $C x$. pipiens

Table 4 Diagnostic value of ace-1 (malathion, bendiocarb) and kdr (lambda-cyhalothrin, permethrin, DTT) alleles for detection of resistance in $C x$. pipiens

\begin{tabular}{|c|c|c|c|c|c|}
\hline & Malathion & Bendiocarb & Lambda-cyhalothrin & Permethrin & DDT \\
\hline Sensitivity, \% (95\% Cl) & $33(20.33-47.11)$ & $21(11.66-33.18)$ & $86(74.21-93.74)$ & $84(69.93-93.36)$ & 87 (73.74-95.06) \\
\hline Specificity, \% (95\% Cl) & $72(56.11-85.40)$ & 95 (83.08-99.39) & $63(48.74-75.71)$ & $26(16.22-37.16)$ & $56(21.20-86.30)$ \\
\hline PPV, \% (95\% Cl) & $61(44.98-74.50)$ & 87 (60.76-96.47) & $71(63.01-77.89)$ & $40(35.85-44.75)$ & 91 (82.69-95.44) \\
\hline NPV, \% (95\% Cl) & $45(38.77-52.02)$ & $44(40.11-47.31)$ & $81(68.41-89.29)$ & 73 (55.39-85.58) & $45(24.41-68.25)$ \\
\hline
\end{tabular}

Abbreviations: $\mathrm{Cl}$ confidence interval, PPV positive predictive values, NPV negative predictive values 
Table 5 Correlation between the frequency of $119 \mathrm{~S}$ allele and insecticide resistant/susceptible phenotypes to malathion and bendiocarb

\begin{tabular}{|c|c|c|c|c|c|c|c|}
\hline \multirow[t]{2}{*}{ Insecticide } & \multirow[t]{2}{*}{ Cx. pipiens form } & \multirow[t]{2}{*}{ Phenotype } & \multirow[t]{2}{*}{$n$} & \multicolumn{2}{|c|}{ G119S alleles } & \multirow[t]{2}{*}{ Odds ratio } & \multirow[t]{2}{*}{$P$-value } \\
\hline & & & & $119 \mathrm{G}(\mathrm{S})$ & $119 S(R)$ & & \\
\hline \multirow[t]{6}{*}{ Malathion } & \multirow[t]{2}{*}{ Cx.p.pipiens } & Susceptible & 30 & 52 & 8 & 1.08 & \multirow[t]{2}{*}{0.875} \\
\hline & & Resistant & 35 & 60 & 10 & $0.40-2.95$ & \\
\hline & \multirow[t]{2}{*}{ Hybrid } & Susceptible & 8 & 13 & 3 & 1.44 & \multirow[t]{2}{*}{0.464} \\
\hline & & Resistant & 12 & 18 & 6 & $0.30-6.87$ & \\
\hline & \multirow[t]{2}{*}{ Cx.p. molestus } & Susceptible & 2 & 4 & 0 & 1.42 & \multirow[t]{2}{*}{0.511} \\
\hline & & Resistant & 5 & 9 & 1 & $0.05-42.25$ & \\
\hline \multirow[t]{6}{*}{ Bendiocarb } & \multirow[t]{2}{*}{ Cx.p.pipiens } & Susceptible & 23 & 45 & 1 & 5.14 & \multirow[t]{2}{*}{0.093} \\
\hline & & Resistant & 39 & 70 & 8 & $0.62-42.54$ & \\
\hline & \multirow[t]{2}{*}{ Hybrid } & Susceptible & 16 & 31 & 1 & 6.20 & \multirow[t]{4}{*}{0.071} \\
\hline & & Resistant & 15 & 25 & 5 & $0.68-56.59$ & \\
\hline & \multirow[t]{2}{*}{ Cx.p. molestus } & Susceptible & 1 & 2 & 0 & na & \\
\hline & & Resistant & 8 & 16 & 0 & na & \\
\hline
\end{tabular}

Abbreviation: na, not applicable

complex to the most commonly used insecticides for vector control. We showed that $C x$. pipiens mosquitoes of the study area presented high resistance levels to PYR ( $\lambda$-cyalothrin and permethrin), OC (DDT), OP (malathion) and CX (bendiocarb). For PYR and DDT, the insecticide with the highest resistance, as shown by death rates, were DDT (16\%), followed by $\lambda$-cyalothrin (46\%) and permethrin $(63 \%)$. Understanding the mechanisms underlying this resistance is essential to guide the use of these chemicals and preserve their efficacy as vector control tools. We also investigated the insecticide target site mutations: G119S ace-1 and L1014F $k d r$. It has been reported that the $k d r$ mutation was closely associated with PYR and DDT resistance in mosquitoes [13, 14, 29-32]. We found that the diagnostic values of the $a c e-1$ and $k d r$ mutations are different: sensitivity is high for the $k d r$

Table 6 Correlation between the frequency of 1014F allele and insecticide resistant/susceptible phenotypes to lambda-cyhalothrin, permethrin and DDT

\begin{tabular}{|c|c|c|c|c|c|c|c|}
\hline \multirow[t]{2}{*}{ Insecticide } & \multirow[t]{2}{*}{ Cx. pipiens form } & \multirow[t]{2}{*}{ Phenotype } & \multirow[t]{2}{*}{$n$} & \multicolumn{2}{|c|}{ L1014F alleles } & \multirow[t]{2}{*}{ Odds ratio } & \multirow[t]{2}{*}{$P$-value } \\
\hline & & & & 1014 L (S) & $1014 \mathrm{~F}(\mathrm{R})$ & & \\
\hline \multirow[t]{6}{*}{ Lambda-cyhalothrin } & \multirow[t]{2}{*}{ Cx.p.pipiens } & Susceptible & 23 & 36 & 10 & 3.87 & 0.0019 \\
\hline & & Resistant & 28 & 27 & 29 & $1.61-9.28$ & \\
\hline & \multirow[t]{2}{*}{ Hybrid } & Susceptible & 25 & 40 & 10 & 4.00 & 0.070 \\
\hline & & Resistant & 20 & 20 & 20 & $1.58-10.14$ & \\
\hline & \multirow[t]{2}{*}{ Cx.p. molestus } & Susceptible & 6 & 9 & 3 & $1 ; 91$ & 0.429 \\
\hline & & Resistant & 9 & 11 & 7 & $3.38-9.59$ & \\
\hline \multirow[t]{6}{*}{ Permethrin } & \multirow[t]{2}{*}{ Cx.p.pipiens } & Susceptible & 28 & 37 & 19 & 2.14 & 0.0023 \\
\hline & & Resistant & 21 & 20 & 22 & $0.94-4.86$ & \\
\hline & \multirow[t]{2}{*}{ Hybrid } & Susceptible & 37 & 42 & 32 & 0.977 & 0.429 \\
\hline & & Resistant & 21 & 27 & 21 & $4.47-2.03$ & \\
\hline & \multirow[t]{2}{*}{ Cx.p. molestus } & Susceptible & 9 & 12 & 6 & 1.50 & 0.746 \\
\hline & & Resistant & 2 & 3 & 1 & $0.13-17.68$ & \\
\hline \multirow[t]{6}{*}{ DDT } & \multirow[t]{2}{*}{ Cx.p.pipiens } & Susceptible & 5 & 9 & 1 & 8.44 & 0.023 \\
\hline & & Resistant & 31 & 32 & 30 & $1.00-70.70$ & \\
\hline & \multirow[t]{2}{*}{ Hybrid } & Susceptible & 2 & 3 & 1 & 4.00 & 0.223 \\
\hline & & Resistant & 14 & 12 & 16 & $0.37-43.40$ & \\
\hline & \multirow[t]{2}{*}{ Cx.p. molestus } & Susceptible & 2 & 2 & 2 & 1.00 & 1 \\
\hline & & Resistant & 1 & 1 & 1 & $0.03-29.83$ & \\
\hline
\end{tabular}


mutation (84-87\%) compared to the ace-1 mutation (21\% and $33 \%)$. On the other hand, the specificity is higher for the ace-1 mutation (72\% and 95\%) compared to the $k d r$ mutation $(26 \%, 56 \%, 63 \%)$.

The leucine (L) to phenylalanine (F) substitution at position 1014 was detected in Cx. pipiens mosquitoes [12]. This study showed that the distribution of the L1014F $k d r$ mutation is widespread, particularly in the pipiens form and hybrids. Our previous report has documented the presence of a $1014 \mathrm{~L} / 1014 \mathrm{~F}$ genotype in three regions of Morocco including Tangier, Casablanca and Marrakech [22]. These results confirmed that the frequencies of $1014 \mathrm{~L} / 1014 \mathrm{~F}$ genotype are variable depending on the area $[31,32]$, and the L1014F $k d r$ mutation is widespread in different sites of Morocco from the North (Tangier) to Marrakech in the South. However, many tested mosquitoes, presenting a resistant phenotype, were also susceptible for the $k d r$ allele 1014F; this result suggests that $k d r$ might not be the only mechanism conferring resistance to PYRs and DDT [33], but other mechanisms can be involved such an overproduction of detoxifying enzymes [34]. Our results are in agreement with those found by other teams [32, 35].

Other mutations were found in Cx. pipiens; the mutation from leucine to serine (TTA to TCA) had been reported in Cx. p. quinquefasciatus $[13,36,37]$ and was also found in $C x$. pipiens complex from China (frequencies ranging between 2.4-28.6\%) [38], Cx. p. pipiens from China and the USA, $C x . p$. quinquefasciatus from the USA and in Cx. pipiens pallens from Japan and China [15]. The L1014C mutation by the substitution of leucine (TTA) to cysteine (TGT) has been reported in many Anopheles species [39-41] and for Cx. P. molestus from China [15].

Mosquitoes with the Phe/kdr mutation displayed a high level of resistance to both pyrethroids and DDT, whereas those with the Ser/kdr mutation displayed a high level of resistance to DDT but a low level of resistance to pyrethroids [12, 42].

$\mathrm{OP}$ and CX are widely used around the world for vector control. The results of this study showed that all forms of the population treated with malathion and bendiocarb exhibit a high level of resistance. G119S is responsible for the reduction of AChE1 activity in cholinergic synapses. It is one of the most common mutations detected in Cx. pipiens mosquitoes [18]. The results showed that G119S mutation was present in the tested population presenting resistant phenotypes. In Morocco in 2002, Faraj et al. [21] found that larvae of $C x$. pipiens developed varying degrees of resistance in four different provinces for certain organophosphates (temephos, chloropyriphos, fenitrothion, pirimiphosmethyl); the highest rates $(>250)$ were recorded in Mohammedia and the lowest in Salé $(<7)$. These results confirmed the presence of significant resistance in $C x$. pipiens for chlorpyriphos and temephos in the prefectures of Mohammedia, Rabat and Skhirat-Témara. Resistance was also important in pyrimiphos-methyl in Mohammedia and malathion in Rabat and Skhirat Témara. In fact, temephos, chlorpyriphos, and pyrimiphos-methyl are widely used in the control of mosquito larvae in these areas, which may explain the high resistance levels to these products. Malathion, on the other hand, has not been reported among the products used in mosquito control by the counties of Rabat. Moreover, by comparing the sensitivity of the different populations of $C x$. pipiens collected from these areas, it was found that this species developed resistance levels that vary according to the prefectures.

Also, the results found by El Ouali Lalami et al. [20], can be explained by the fact that chlorpyriphos and temephos are insecticides widely used in the control of mosquito larvae in the study area of Fez. The highest resistance level (14.34) to temephos was obtained in Sidi Hrazem, and the lowest (12.17) was recorded in the Hafat Moulay Driss. The resistance rates of the $C x$. pipiens species to temephos recorded in the city of Fez were higher than the rates recorded in the prefecture of Sale but lower than those recorded in the prefectures of Temara, Rabat and Mohammedia. These observations are consistent with those reported in Tunisia by Kooli \& Rhaiem [43], who reported that a high level of resistance was acquired in urban larval populations of $C x$. pipiens after several treatments with organophosphates. Other authors [44] also reported high levels of resistance of $C x$. pipiens larvae to temephos and fenthion (resistance ratios 129.23 and 115.56, respectively).

The resistance levels observed, if not due to intensive prior use, can only be explained by the acquisition of cross-resistance. Indeed, Sinegre et al. [45] found in $C x$. pipiens treated with chlorpyriphos, the appearance of resistance to other organophosphates. Chavasse \&Yap [46] were able to confirm that the prolonged use of an organophosphorus always leads to the appearance of cross-resistance to other organophosphates and sometimes to certain products of the carbamate family. Indeed, Sinegre et al. [47] were able to establish an obvious correlation between the degrees of resistance and the frequency of insecticide treatments. On the French Mediterranean coast, for example, a resistance rate of 60 was reached after seven years of regular control of $C x$. pipiens larvae with chlorpyriphos [48]. According to the same author, it increased until a resistance rate of 330 in some areas after ten years of use. The high rates of resistance found in our study could be explained by the appearance of cross-resistance, especially when the area was treated only with temephos for larvae and PYR for adults.

Our results showed no correlation between the resistant phenotype and the presence of the G119S mutation. 
This result can be explained by the implication of metabolic mechanisms with overproduction of detoxifying enzymes. Target site modification coupled with enzyme detoxification has been described in An. gambiae and Cx. quinquefasciatus from Benin [49]. Other studies have demonstrated the likely implication of metabolic mechanisms in resistance to bendiocarb [50]. There is also a need for a future study to investigate metabolic resistance like glutathione S-transferase, carboxylesterase, and cytochrome $\mathrm{P} 450$ monooxygenase activity to elucidate the mechanisms of resistance to the currently used insecticides in vector control.

\section{Conclusion}

The use of insecticides for vector control had been achieved in Morocco for a long time. The results of bioassays and molecular identification of target-site mutations showed clearly that $C x$. pipiens mosquitoes from Mohammadia were resistant to all tested insecticides. The frequencies of resistant $a c e-1$ and $k d r$ alleles carrying the G119S and L1014F substitution are dramatically high for $C x$. pipiens populations collected in the study site. Hence it is pivotal that policy makers and program implementers recognize the growing threat posed by insecticide resistance and strive to integrate resistance management into all control programs.

\section{Abbreviations}

AChE1: Acetylcholinesterase-1 enzyme; Cx: Carbamates;

DDT: Dichlorodiphenyltrichloroethane; GABA: Gamma-amino butyric acid; Kd: Knockdown; kdr: Knockdown resistance; OP: Organophosphates; OR: Odds ratio; PYR: Pyrethroids; RVFV: Rift Valley fever virus; ULV: Ultra-low volume; WHO: World Health Organization; WNV: West Nile virus

\section{Acknowledgments}

We thank Dr Sayeh Ezzikouri from Institute Pasteur of Morocco for help with statistical analysis.

\section{Funding}

This work was supported by the Institute Pasteur of Morocco.

\section{Availability of data and materials}

All data generated or analyzed during this study are included in this published article.

\section{Authors' contributions}

FZT performed the experiments, mosquito collections, analyzed the data and wrote the paper. CF participated in analysis and interpretation of bioassay test results. $\mathrm{MB}$ contributed to laboratory analysis. $\mathrm{KM}$ participated in the design of experiments. ABF participated in the design of experiments and revised the draft. MS participated in the design of experiments, mosquito collections and revised the draft. All authors read and approved the final manuscript.

\section{Ethics approval and consent to participate}

Not applicable.

\section{Consent for publication}

Not applicable.

\section{Competing interests}

The authors declare that they have no competing interests.

\section{Author details}

${ }^{1}$ Institut Pasteur du Maroc, Service de Parasitologie et des Maladies Vectorielles, Place Louis Pasteur, 20360 Casablanca, Morocco. ${ }^{2}$ Faculté des Sciences Ain-Chock, Laboratoire de Physiopathologie, Génétique Moléculaire et Biotechnologie, Casablanca, Morocco. ${ }^{3}$ Institut National d'Hygiène, Laboratoire d'Entomologie Médicale, Rabat, Morocco. ${ }^{4}$ Institut Pasteur, Department of Virology, Arboviruses and Insect Vectors, 25-28 rue du Docteur Roux, 75724 Paris, France.

Received: 29 March 2017 Accepted: 8 January 2018

Published online: 22 January 2018

\section{References}

1. Murgue B, Murri S, Triki H, Deubel V, Zeller HG. West Nile in the Mediterranean Basin: 1950-2000. Ann N Y Acad Sci. 2001;951:117-26.

2. Zeller HG, Schuffenecker I. West Nile virus: an overview of its spread in Europe and the Mediterranean basin in contrast to its spread in the Americas. Eur J Clin Microbiol Infect Dis. 2004;23:147-56.

3. Moutailler S, Krida G, Schaffner F, Vazeille M, Failloux A-B. Potential vectors of Rift Valley fever virus in the Mediterranean region. Vector-Borne Zoonotic Dis. 2008;8:749-54.

4. Krida G, Diancourt L, Bouattour A, Rhim A, Chermiti B, Failloux A-B. Estimation du risque d'introduction du virus de la fièvre de la vallée du Rift en Tunisie par le moustique Culex pipiens. Bull Société Pathol Exot. 2011;104:250-9.

5. Tber AA. West Nile fever in horses in Morocco. Bull OIE. 1996;108:867-9.

6. Schuffenecker I, Peyrefitte CN, el Harrak M, Murri S, Leblond A, Zeller HG. West Nile virus in Morocco, 2003. Emerg Infect Dis 2005;11:306-309.

7. Ben Hassine T, Hammami S, Elghoul H, Ghram A. Détection de la circulation de virus West Nile chez les Équidés dans le nord-ouest de la Tunisie. Bull Société Pathol Exot. 2011;104:266-71.

8. Hollingworth RM, Dong K. The biochemical and molecular genetic basis of resistance to pesticides in arthropods. Global pesticide resistance in arthropods. Wallingford: CAB International; 2008. p. 40-89.

9. Labbé P, Alout H, Djogbénou L, Pasteur N, Weill M. Evolution of resistance to insecticide in disease vectors. In: Genetics and evolution of infectious disease. London: Elsevier; 2011. p. 363-409.

10. Ranson H, N'Guessan R, Lines J, Moiroux N, Nkuni Z, Corbel V. Pyrethroid resistance in African anopheline mosquitoes: what are the implications for malaria control? Trends Parasitol. 2011;27:91-8.

11. Soderlund DM, Knipple DC. The molecular biology of knockdown resistance to pyrethroid insecticides. Insect Biochem Mol Biol. 2003;33:563-77.

12. Martinez-Torres D, Chevillon C, Brun-Barale A, Bergé JB, Pasteur N, Pauron D. Voltage-dependent $\mathrm{Na}+$ channels in pyrethroid-resistant Culex pipiens $\mathrm{L}$. mosquitoes. Pest Manag Sci. 1999;55:1012-20.

13. Xu Q, Wang H, Zhang L, Liu N. Kdr allelic variation in pyrethroid resistant mosquitoes, Culex quinquefasciatus (S.). Biochem Biophys Res Commun. 2006;345:774-80.

14. Martinez-Torres D, Chandre F, Williamson MS, Darriet F, Berge JB, Devonshire AL, et al. Molecular characterization of pyrethroid knockdown resistance $(k d r)$ in the major malaria vector Anopheles gambiae s.s. Insect Mol Biol. 1998;7:179-84.

15. Scott JG, Yoshimizu M, Kasai S. Pyrethroid resistance in Culex pipiens mosquitoes. Pest Biochem Physiol. 2015;120:68-76.

16. Massoulié J, Bon S. L'acétylcholinestérase: une structure originale pour une fonction vitale. In: Annales de l'Institut Pasteur. Actualités. Paris, France: Elsevier; 1993. p. 35-49.

17. Mutero A, Pralavorio M, Bride J-M, Fournier D. Resistance-associated point mutations in insecticide-insensitive acetylcholinesterase. Proc Natl Acad Sci USA. 1994:91:5922-6.

18. Weill M, Lutfalla G, Mogensen K, Chandre F, Berthomieu A, Berticat C, et al. Comparative genomics: insecticide resistance in mosquito vectors. Nature. 2003:423:136-7.

19. Alout H, Djogbénou L, Berticat C, Chandre F, Weill M. Comparison of Anopheles gambiae and Culex pipiens acetycholinesterase 1 biochemical properties. Comp Biochem Physiol B Biochem Mol Biol. 2008;150:271-7.

20. El Ouali LA, El-Akhal F, El Amri N, Maniar S, Faraj C. État de la résistance du moustique Culex pipiens vis-à-vis du téméphos au centre du Maroc. Bull Société Pathol Exot. 2014;107:194-8.

21. Faraj C, El Kohli M, El Rhazi M, Laqraa M, Lyagoubi M. Niveau actuel de la résistance du moustique Culex pipiens aux insecticides au Maroc. Sci Lett. 2002;4:4p. 
22. Bkhache M, Tmimi F-Z, Charafeddine O, Faraj C, Failloux A-B, Sarih M. First report of L1014F-kdr mutation in Culex pipiens Complex from Morocco. Parasit Vectors. 2016;9:644.

23. Brunhes J, Rhaim A, Geoffroy B, Angel G, Hervy J-P. Les moustiques de I'Afrique méditerranéenne: logiciel d'identification et d'enseignement. IRD \& IPT, CD-Rom collection didactique, Éditions IRD: Montpellier, France; 2000.

24. World Health Organization. Test procedures for insecticide resistance monitoring in malaria vector mosquitoes. Geneva: WHO; 2013.

25. Bahnck CM, Fonseca DM. Rapid assay to identify the two genetic forms of Culex (Culex) pipiens L. (Diptera: Culicidae) and hybrid populations. Am J Trop Med Hyg. 2006;75:251-5.

26. Weill M, Malcolm C, Chandre F, Mogensen K, Berthomieu A, Marquine M, et al. The unique mutation in ace-1 giving high insecticide resistance is easily detectable in mosquito vectors. Insect Mol Biol. 2004;13:1-7.

27. Zaim M, Aitio A, Nakashima N. Safety of pyrethroid-treated mosquito nets. Med Vet Entomol. 2000;14:1-5.

28. WWF. Hazards and exposures associated with DDT and synthetic pyrethroids used for vector control: World Wildlife Fund; 1999.

29. Brengues C, Hawkes NJ, Chandre F, McCarroll L, Duchon S, Guillet P, et al. Pyrethroid and DDT cross-resistance in Aedes aegypti is correlated with novel mutations in the voltage-gated sodium channel gene. Med Vet Entomol. 2003;17:87-94.

30. Enayati AA, Vatandoost $\mathrm{H}$, Ladonni $\mathrm{H}$, Townson $\mathrm{H}$, Hemingway J. Molecular evidence for a $k d r$-like pyrethroid resistance mechanism in the malaria vector mosquito Anopheles stephensi. Med Vet Entomol. 2003;17:138-44.

31. Gnanguenon V, Agossa FR, Badirou K, Govoetchan R, Anagonou R, Oke-Agbo F, et al. Malaria vectors resistance to insecticides in Benin: current trends and mechanisms involved. Parasit Vectors 2015;8:223.

32. Niangel HA, Konaté L, Diallo M, Faye O, Dia I. Patterns of insecticide resistance and knock down resistance $(k d r)$ in malaria vectors An. arabiensis, An. coluzzii and An. gambiae from sympatric areas in Senegal. Parasit Vectors. 2016;9:71.

33. Brooke BD. $k d r$ : can a single mutation produce an entire insecticide resistance phenotype? Trans R Soc Trop Med Hyg. 2008;102:524-5.

34. Ibrahim SS, Manu YA, Tukur Z, Irving H, Wondji CS. High frequency of $k d r$ L1014F is associated with pyrethroid resistance in Anopheles coluzzii in Sudan savannah of northern Nigeria. BMC Infect Dis. 2014;14:441-9.

35. Samb B, Konate L, Irving H, Riveron JM, Dia I, Faye O, et al. Investigating molecular basis of lambda-cyhalothrin resistance in an Anopheles funestus population from Senegal. Parasit Vectors. 2016;9:449.

36. Xu Q, Tain L, Zhang L, Liu N. Sodium channel genes and their differential genotypes at the L-to-F kdr locus in the mosquito Culex quinquefasciatus. Biochem Biophys Res Commun. 2011;407:645-9.

37. Liu N. Xu Q, Li T, he L, Zhang L. Permethrin resistance and target site insensitivity in the mosquito Culex quinquefasciatus in Alabama, USA. J Med Entomol. 2009;46:1424-9.

38. Wang ZM, Li CX, Xing D, Yu YH, Liu N, Xue RD, et al. Detection and widespread distribution of sodium channel alleles characteristic of insecticide resistance in Culex pipiens complex mosquitoes in China. Med Vet Entomol. 2012;26:228-32.

39. Diabate A, Brengues C, Baldet T, Dabiré KR, Hougard JM, Akogbeto, et al. The spread of the Leu-Phe kdr mutation through Anopheles gambiae complex in Burkina Faso: genetic introgression and de novo phenomena. Tropical Med Int Health. 2004;9:1267-73.

40. Syafruddin D, Hidayati AP, Asih PB, Hawley WA, Sukowati S, Lobo NF. Detection of $1014 \mathrm{~F} k d r$ mutation in four major anopheline malaria vectors in Indonesia. Malar J. 2010;9:315.

41. Tan WL, Wang ZM, Li CX, Chu HL, Xu Y, Dong YD, et al. First report on co-occurrence knockdown resistance mutations and susceptibility to beta-cypermethrin in Anopheles sinensis from Jiangsu Province. China. PLoS One 2012;7(1):e29242.

42. Burton MJ, Mellor IR, Duce IR, Davies TG, Field LM, Williamson MS. Differential resistance of insect sodium channels with $k d r$ mutations to deltamethrin, permethrin and DDT. Insect Biochem Mol Biol 2011;41:723-732.

43. Kooli J, Rhaiem A. Sensibilité des larves de moustiques aux insecticides dans la région de Tunis de 1984 à 1988. Arch Inst Pasteur Tunis. 1989;66:61-71.

44. Dong CL, Young-Joon A. Laboratory and simulated field bioassays to evaluate larvicidal activity of Pinus densiflora hydrodistillate, its constituents and structurally related compounds against Aedes albopictus, Aedes aegypti and Culex pipiens pallens in relation to their inhibitory effects on acetylcholinesterase. Activity. Insects. 2013;4:217-29.
45. Sinegre G, Gaven B, Jullien J. Activité comparée de 31 insecticides sur des larves de Culex pipiens (L.) sensibles et résistantes au chlorpyriphos dans le midi de la France. Parassitologia. 1977;19:63-72.

46. Chavasse D, Yop H. Chemical methods for the control of vectors and pests of public health importance, vol. 2: WHO/CTD/WHOPES/; 1997. p. 129.

47. Sinegre G, Jullien J, Gaven B. Acquisition progressive de la résistance au chlorpyriphos chez les larves de Culex pipiens (L.) dans le midi de la France. Parasitologia. 1977;19:1-2.

48. Sinegre G. La résistance des diptères culicides en France. Quatrième colloque organisé par la commission d'étude des conséquences de la protection des plantes sur les biocénoses de la société française de phytiatrie et phytopharmacie, Paris, le 20 mars 1984;11.

49. Yadouléton A, Badirou K, Agbanrin R, Jöst H, Attolou R, Srinivasan R, et al. Insecticide resistance status in Culex quinquefasciatus in Benin. Parasit Vectors. 2015:8:17.

50. Antonio-Nkondjio C, Poupardin R, Tene BF, Kopya E, Costantini C, Awono-Ambene $P$, et al. Investigation of mechanisms of bendiocarb resistance in Anopheles gambiae populations from the city of Yaoundé. Cameroon Malar J. 2016;15:424-35.

\section{Submit your next manuscript to BioMed Central and we will help you at every step:}

- We accept pre-submission inquiries

- Our selector tool helps you to find the most relevant journal

- We provide round the clock customer support

- Convenient online submission

- Thorough peer review

- Inclusion in PubMed and all major indexing services

- Maximum visibility for your research

Submit your manuscript at www.biomedcentral.com/submit
Biomed Central 